\title{
Clinical Trial Subject Participation Form
}

National Cancer Institute

\section{Source}

National Cancer Institute. Clinical Trial Subject Participation Form. NCI Thesaurus. Code

C115519.

Documentation that identifies a subject as a participant in a clinical trial. 